\title{
DISCUSSION
}

\section{Determination of shear strength of Hawaiian residual soil subjected to rainfall-induced landslides}

\author{
J.-H. ZHU and S.A. ANDERSON (1998). Géotechnique 48, No. 1, 73-82
}

\section{Y. Tsukamoto, Science University of Tokyo}

The authors have presented interesting, carefully performed test results on clayey soils subjected to rainfall-induced soil failure. The discusser fully agrees with the importance of a laboratory simulation of the failure stress path for the determination of shear strength of the soils concerned. To examine the cause and the initiation of the rainfall-induced soil failures, the discusser was also inspired by the work of Anderson \& Sitar (1995), and has some experience in conducting a series of anisotropically consolidated undrained (ACU) triaxial compression tests and constant shear drained (CSD) tests (Tsukamoto et al., 1998). This discussion is aimed at bringing some additional test results and comments to this technical paper, and at seeking some comments from the authors.

Heavy rainfall attacked the Boso Peninsula, Chiba, Japan, in 1971, and caused numerous slope failures at several locations including the Omigawa area. The soil mechanics group at the Science University of Tokyo has recently visited several sites to re-examine the cause of these shallow-depth slope failures induced by the heavy rainfall, and has retrieved soil samples from the Omigawa area. The soil was poorly graded sand-silt mixtures with non-plastic fines, and the physical properties of the soil were as follows: $G_{\mathrm{s}}=2.694, e_{\max }=1.282, e_{\min }=$ $0.796, D_{50}=0.16 \mathrm{~mm}$, and fines content, $F_{\mathrm{c}}=8 \%$. A series of ACU tests as well as CSD tests were conducted on reconstituted soil specimens. As illustrated by the authors as well as
Anderson \& Sitar (1995), the significance of performing CSD tests lies in the fact that the technique can simulate the reduction in effective stress caused by saturation and then water infiltration due to rainfall, which leads to the initiation of slope failures.

Figure 6 shows the CSD test results for the Omigawa soil, where $p^{\prime}=\left(\sigma_{1}+\sigma_{3}\right) / 2, q=\left(\sigma_{1}-\sigma_{3}\right) / 2, \quad \varepsilon_{1}$ is the axial strain, and $\varepsilon_{\mathrm{v}}$ is the volumetric strain. The soil samples were retrieved from the deposits at the foot of the slope, and therefore were in a state in which all the bonded structures and the inherent soil fabrics were completely destroyed. The steady-state envelope and steady-state line obtained from the isotropically consolidated undrained (ICU) triaxial compression tests are also plotted in Fig. 6(a) and Fig. 6(b) respectively. All the test results showed dilative behaviour, in which the void ratios become large as a result of the reduction in effective mean stress, except for tests $\mathrm{H}$ and I, which correspond to unrealistically loose specimens.

Experimental observations of the test results similar to those of the authors can be made. However, it can be seen that the failure envelope at which the CSD specimens were subjected to a reduction in shear stress is not significantly different from the steady-state envelope determined by the ICU tests. It was also later found that this failure envelope was not significantly different from the steady-state envelope determined by the ACU tests either. From the ACU tests performed on the Omigawa soil

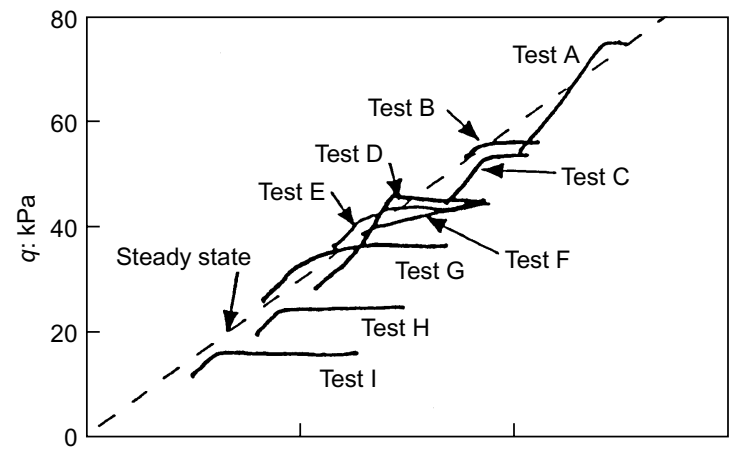

(a)

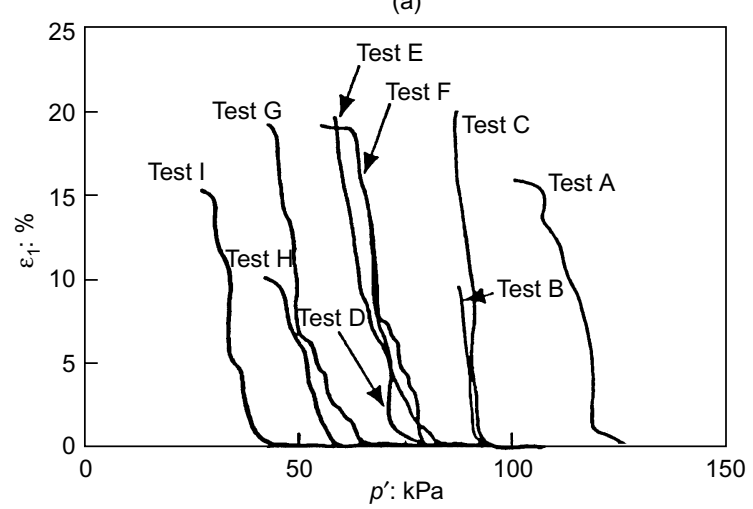

(c)

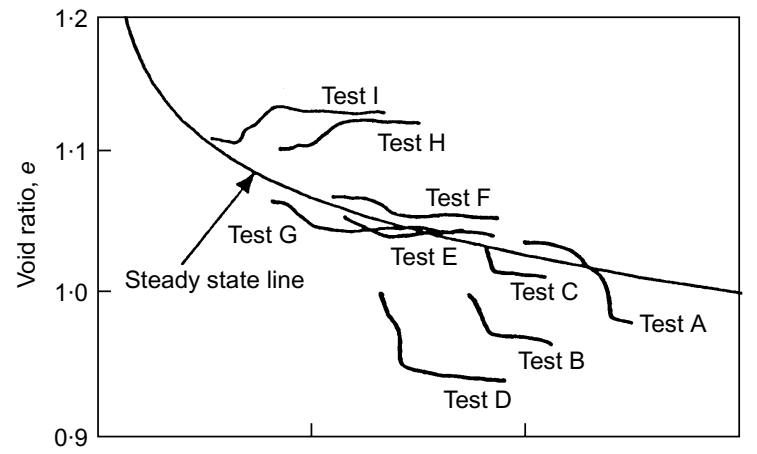

(b)

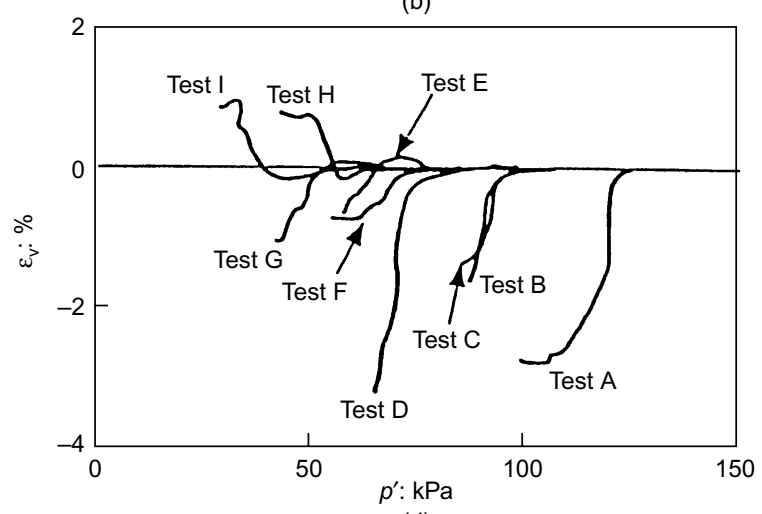

(d)

Fig. 6. CSD results on Omigawa soil (after Tsukamoto et al., 1998), plotted against $p^{\prime}=\left(\sigma_{1}+\sigma_{3}\right) / 2:\left(\right.$ a) $q=\left(\sigma_{1}-\sigma_{3}\right) / 2 ;(b)$ void ratio, e; (c) axial strain, $\varepsilon_{1}$; (d) volumetric strain, $\varepsilon_{\mathrm{v}}$ 
it was also found that almost all the effective stress paths on the $p^{\prime}-q$ diagram for anisotropically consolidated undrained tests show peaks and then drop off, and some of them rise again along the steady-state envelope, to achieve the largely deformed steady states. However, the peak points on the $p^{\prime}-q$ diagram were within the steady-state envelope and did not exceed it.

It is noteworthy that the effective stress paths of the Hawaiian residual soil in Fig. 4 experience peaks (yields) at positions higher than the large-strain envelope, and therefore the yield envelope is located higher than the large-strain envelope. As the authors point out, this could be due to the bonded structures built within the soils: in other words, due to the effects that cementation has on the shearing resistance of soils, since this residual soil contains $25-35 \%$ of silty and clayey materials. Therefore the determination of the shearing resistance with respect to the yield envelope for this residual soil had to take advantage of the quality of the undisturbed soil samples, which maintain the original soil fabric as well as bonded structures.
However, there may be a regional variation in the degree of cementation developed within the soils, and also undisturbed soil samples may not be easily available.

With the absence of such intact soil samples, it might be more advantageous to provide a rather conservative solution by relying upon the largely deformed envelope, or some other envelopes located lower than the largely deformed envelope, such as the phase transformation line, to evaluate the stability of the slope and the initiation of the slope failure.

\section{REFERENCES}

Anderson, S. A. \& Sitar, N. (1995). Analysis of rainfall-induced debris flows. J. Geotech. Engng, ASCE 121, No.7, 544-553.

Tsukamoto, Y., Ishihara, K. \& Nosaka, Y. (1998). On the initiation of rainfall induced soil failure. Proc. 11th Danube-Eur. Conf. Soil Mech. Geotech. Engng: Geotechnical Hazards (eds B. Maric, Z. Lisac \& A. Szavits-Nossan), pp. 883-890. Rotterdam: Balkema. 